\title{
El fenómeno festivo en la Daroca del siglo XVI: prácticas cotidianas y ceremoniales públicos
}

\author{
José Antonio Mateos Royo*
}

\begin{abstract}
ARESUMEN
ABSTRACT

Articulo relativo a las festividades $y$

This paper studies the festivites and ceremonias que tuvieron lugar en la ciudad aragonesa de Daroca durante el siglo xvi. La investigación muestra la convivencia entre las variadas manifestaciones de la "cultura popular», en pleno auge, con los ceremoniales cada vez más espléndidos vinculados a la ceremonies that took place in the Aragonese town of Daroca during the sixteenth century. The research shows the coexistence of a huge variety of popular culture manifestations in their prime, together with increasingly splendid monarchist civic ceremonies. However, the Counter Reformation monarquia. Sin embargo, la incidencia introduced a more religious and tragic de la Contrarreforma a fines del siglo $x v$ introduce un concepto más trágico

$y$ religioso de la festividad. Su influencia propiciará el progresivo predominio de la "cultura oficial" sobre la "Cultura popular" en el siglo concept of the festivity at the end of the sixteenth century. Its influence produced as a result the progressive supremacy of the "official culture" over the "popular culture" during the seventeenth century.
\end{abstract}

siguiente.

* Departamento de Historia Moderna y Contemporánea. Universidad de Zaragoza. 
En el contexto de expansión general -económica, demográfica, cultural- que supone la centuria del Quinientos, la ciudad de Daroca, municipio aragonés de realengo, conoce una amplia variedad de manifestaciones festivas. Algunas demuestran de forma evidente una herencia medieval, otras se revelan hijas del nuevo siglo. Unas se vinculan al ámbito de lo cotidiano y la cultura popular ', asociadas a iglesias o cofradías, o a su misma práctica por el pueblo a través de la tradición o costumbre. Otras, en fin, se hallan más relacionadas con la actuación del Concejo como institución que asume el expresar el sentimiento de la ciudad con motivo de ciertos acontecimientos, en su mayoría vinculados a la institución monárquica. El presente artículo pretende indagar en todas estas prácticas para lograr una caracterización del fenómeno festivo en la ciudad, determinar sus causas, así como fijar sus consecuencias cara a su evolución en los siglos siguientes de la Edad Moderna.

\section{EL CONTEXTO COTIDIANO}

\subsection{Las festividades religiosas}

En Daroca el ciclo festivo venía condicionado de forma primordial, al igual que sucede en muchos otros lugares, por el Corpus Christi. Esta celebración cobraba especial significado en Daroca al hallarse asociada la ciudad al milagro de los Santos Corporales, objeto de veneración desde la Baja Edad Media ${ }^{2}$. Favorecida por la existencia de una feria para estas fechas, Daroca se llenaba de peregrinos procedentes tanto de la comarca como de otros lugares con la ilusión de ver las reliquias de los Corporales, expuestas ese día en un edificio extramuros - véase el

Sobre el concepto cultura popular, véase BuRkE, P.. La cultura popular en la Europa Moderna, Madrid, Alianza, 1990; ChARTtE, R., “Construction de l'État moderne et formes culturelles. Perspectives et questions", en Culture et ideologie dans la génese de l'État Moderne. Roma. Escuela Francesa de Roma, 1985, págs. 491-503; REVEI, J., «La culture populaire: sur les usages et les abus d'un outil historiographique", en Culturas populares. Diferencias, divergencias, conflictos. Madrid, Universidad Complutense, 1986, págs. 225-239; MuChEmBLED, R., Culture populaire et culture des élites dans la France Moderne ( $x$ v-xvil siècle). Paris. Flammarion, 1991 y BERCE.

Y. M. Fête et revolte. Des mentalités populaires du xvi au xvil siècle. Paris, Hachette, 1994.

Sobre la institucionalización y desarrollo del Corpus Christi en Aragón y Daroca. véase FALCON, M. I., "La procesión del Corpus en Zaragoza en el siglo xv", en Estado actual de los Estudios sobre Aragón. Actas de las V Jornadas. Zaragoza. Universidad, 1984, págs. 633-638 y PÉREZ, L., "Juglares y ministriles en la procesión del Corpus de Daroca en los siglos XV y XVI", Nassarre, VI, 1 (1990), págs. 85-177. Como aportación más actualizada sobre el tema de los Corporales, Corral, J. L., "Una Jerusalén en el Occidente medieval: la ciudad de Daroca y el milagro de los Corporales", Aragón en la Edad Media, Xll (1995), págs. 61-122. 
mapa adjunto- denominado la Torreta. Las disposiciones municipales para la festividad son fiel trasunto de las empleadas en la Edad Media. Se ordenaba disponer colgaduras en las paredes, las calles eran limpiadas y enarenadas, aneas y cañamazos se extendían ante el paso de las Sagradas Formas y músicos contratados por el Concejo amenizaban el transcurso del cortejo.

Junto al Corpus, la festividad de Nuestra Señora de Agosto cobra fuerza en la ciudad desde principios del siglo XVI. En evidente contraste con el siglo anterior, será una de las fiestas más cuidadas por el Concejo, quien durante los siglos XVI y XVII costeará de forma regular los gastos derivados de la procesión de Nuestra Señora, consistentes en la quema de hierbas aromáticas (incienso, estoraque, benjuí) y de velas de cera, el arreglo de la cama donde era transportada la imagen - el bulto- de la Virgen, así como su transporte en andas escoltada por clérigos bajo la apariencia de los doce apóstoles y cuatro reyes. Ya a fines del siglo, la festividad de Santo Tomás Aquino se verá también afirmada para convertirse en el siglo $x V I I$, junto a las dos anteriores, en una de las tres principales fiestas religiosas de la ciudad. Por el contrario, votos explícitos por parte del municipio, como los realizados a San Cristóbal o a Santa Ana en julio y octubre de 1492 con motivo de la amenaza de peste que se cernía ese año sobre la ciudad ${ }^{3}$ no tendrán apenas reflejo en las actuaciones concretas del Concejo durante las dos centurias siguientes.

Al respecto, resulta necesario destacar la influencia municipal en el desarrollo de celebraciones a tono con la Contrarreforma católica. Así, el Concejo aprovechará el oportuno rumor de un milagro acaecido en Luchente en el Corpus de 1564 relativo al Misterio de los Corporales para difundir el culto a Santo Tomás de Aquino ${ }^{4}$, defensor del dogma de la Transubstanciación. En 1584 comisionará a un religioso para procurarse una reliquia del santo, cuya fiesta propone al clero en 1589. Su consagración definitiva se alcanza en los grandes festejos que se le dedican en 1595 y de nuevo en 1600, al atribuírsele el fin de la peste que asolaba Daroca. En 1643, a requerimiento del papa Urbano VIII, el Concejo confirma la elección de Santo Tomás como patrón de la ciudad.

Vinculadas a santos constituidos en sus patrones, en Daroca tenían lugar a lo largo del año buen número de procesiones desarrolladas por iglesias, conventos y cofradías. Así, por ejemplo, en 1518 el capítulo ge-

AMD. Libro de Estatutos (10.7.1), fol. 128v-129v.

AMD, Act Mun, 1564, 4 y 5 de marzo, 1565, 11 de mayo, 1568, 27 de feb, 1584, 16 de marzo, 1589, 10 de marzo, 1595, 10, 12 y 17 de feb, 1596, 3 de mayo, 1643, 4 de abril. 
neral de las seis iglesias de Daroca -excluida la Colegial- solicita permiso al Concejo para salir en procesión para San Gorgonyo, los frailes de San Blas para San Lázaro, los frailes de San Lázaro para Nuestra Señora del Rosario y los franciscanos, con motivo de la festividad de San Francisco ${ }^{5}$. Al municipio competía, por tanto, regular los principales festejos vinculados a estas instituciones:

“Providieron que el día de San Martín se haga processión a San Nicasio y buervan a San Pedro. $Y$ el dia de San Valero se haga processión a San Valero. Y diputaron a Jaime Savastian y a Pedro de Huerta para hablar con capitol general ${ }^{6}$.

A suplicación de los coffadres de San Lorenz, la ciudat les dió processión a San Blas por el día de San Lorenz. Y el Justicia diputó para hablar con el clero a Joan d'Alava d’Odonz y a Pedro de León» ' .

Por supuesto, al margen de las festividades ligadas a su patrón respectivo, todas estas instituciones religiosas podían adherir sus imágenes, cruces y estandartes a conmemoraciones de carácter más general. El mismo año de 1518, el convento y la cofradía de San Blas solicita al Concejo que «el dia de Corpus Christi salga la cabeza de San Blas en la procesión" ${ }^{8}$, es decir, la imagen con forma de busto del santo, según costumbre acreditada para otras procesiones del Corpus como las celebradas en Zaragoza durante el siglo Xv. Dada la importancia simbólica concedida al ceremonial durante las Edades Media y Moderna, esta participación general en los cortejos procesionales daba lugar a constantes conflictos. Clérigos y cofrades disputaban entre sí por obtener los puestos de privilegio - que solían ser los últimos- en la comitiva.

"En lo que Antón Cutanda y otros confadres de señor Sanct Mames han representado que en Nuestra Señora de los Corporales los canónigos quieren sacar en las procesiones la cabeça de señora sancta Anna detrás de la de Nuestra Señora de Nazaret, que se les haga merced de hablar con dichos canónigos para que vaya la cabeça de Nuestra Señora en su lugar. Todo el Consejo deliberó que los otros confadres se compongan con los canónigos y si quisieren salir en las procesiones salgan primero o no salgan" 9 .

Ibidem, 1518, 25 de junio, 6 de agosto, 3 de sept, 1 de oct.

lbidem, 1524, 15 de enero.

Ibidem, 1524, 5 de agosto.

8 Ibidem, 1518, 26 de marzo. Sobre Zaragoza, véase FALCON, M. I., "La procesión del Corpus en Zaragoza durante el siglo XV”, en Estado actual de los Estudios sobre Aragón. Actas de las V Jornadas. Zaragoza, Universidad, 1984, págs. 635 y 637 . En concreto, se citan la presencia en diversas procesiones de los bustos-relicarios de Santa Engracia, San Lamberto, Santa Bárbara y San Braulio.

9 AMD, Act Mun, 1595, 11 de agosto. 
En general, la buena situación económica de la centuria contribuyó a dar mayor magnificencia a todos estos rituales al permitir a estas asociaciones adquirir retablos, comprar imágenes, renovar casullas y cruces procesionales o remozar capillas y ermitas, las cuales eran objeto de peregrinación en la festividad del patrón de la cofradía. El municipio favoreció esta tendencia al conceder de forma condicionada a las cofradias los derechos de percibir ciertos impuestos menores ${ }^{10}$, así como sumas de dinero y piezas de terreno para edificar ermitas. De este modo, al suplicar en 1568 los cofrades de San Julián ${ }^{11}$ al Concejo permiso para vender el edificio que habian comenzado a levantar para ermita, éste les recordará su uso exclusivo como lugar de devoción y templo.

Por desgracia, una descripción del número de las cofradías existentes en el siglo XVI en Daroca y de sus prácticas concretas se revela por el momento imposible. Algunas agrupaban a los inmigrantes procedentes de determinadas zonas geográficas, como la de la Asunción, también llamada de los vizcaínos, que disponía de una capilla propia en la iglesia Colegial. Otras se hallaban vinculadas al desempeño de ciertos oficios artesanales, como la de Santa Lucía, que agrupaba a los sastres. Otras se centraban de forma exclusiva en fines asistenciales, como la de Nuestra Señora de la Merced, que regentaba el principal Hospital de la ciudad. Otras, en fin, se veían caracterizadas por cometidos específicos de diversa índole, como la de San Vicente, que asumía la limpieza del pozo del mismo nombre sito en la ciudad.

De entre todas las cofradías, la mejor documentada en sus manifestaciones festivas es la cofradía de San Juan y San Jorge. La compra de armas y pólvora desarrollada por el Concejo darocense como medida de precaución ante el levantamiento morisco de las Alpujarras tuvo como imprevista consecuencia a fines del siglo XVI el uso con fines lúdicos del material bélico adquirido por la ciudad ${ }^{12}$ en entradas reales o festividades ciudadanas: en 1596, por ejemplo, se encarga a Domingo Carín la construcción de un castillo de fuegos artificiales para Santo Tomás de Aquino. Las manifestaciones más constantes de estas prácticas se vincularán, sin embargo, a la citada cofradía ${ }^{13}$, cuyos miembros acostumbraban a realizar

10 El mejor ejemplo es la percepción de las penas de las cuestas, cedida ya a mediados del xVI a las cofradías de San Valero y San Juan. El Concejo decide en 1557 rescindirles este derecho debido a su mal uso, pero en 1589 se volverá a proponer su cesión a las cofradías. Véase AMD Act Mun, 1557, 12 de feb, 1589, 22 de sept.

lbidem, 1568, 23 de enero.

Ibidem, 1575, 11 de marzo, 1578, 11 de agosto, 1596, 3 de mayo.

13 Ibidem, 1578, 27 de junio, 1589, 21 de junio, 1595, 16 de junio, 1596, 21 de junio y APND, 1581, Pablo Pastrana. (1084), 23 de junio y 1587, Tomás Zorrilla (1479), 19 de junio. Días antes de la fiesta, el Concejo entregaba al preboste y cofrades de San Juan y San Jorge algunas libras de pólvora de las custodiadas en la torre homónima, que servía de almacén a la ciudad 
en junio para San Juan Bautista por la mañana un alarde o desfile militar caracterizado por el abundante uso de pólvora. Constituye en esencia un claro precedente de la difusión de las soldadescas por Daroca y su comarca durante la segunda mitad del siglo XVII gracias a las armas de fuego y pólvora acumuladas para la guerra de Cataluña.

La tendencia expansiva de las cofradías constatada a lo largo del Quinientos parece cobrar nuevos impulsos en el último tercio de siglo ${ }^{14}$. En agosto de 1565 el Concejo otorga licencia para «hazer la confadría de Nuestra Señora de Nazaret y de Sant Mames, solamente para las obras pias». En 1568 se solicita permiso para formar la cofradía de la Sangre de Cristo. En 1584 el padre Guerrero presenta al Concejo indulgencias e instrucciones destinadas a "hazer una confadría de Nuestra Señora de la Soledad para el Viernes Santo".

Por norma general, estas cofradías se van revistiendo de un nuevo carácter. Frente a las advocaciones más tradicionales de santos vinculados a la localidad, como Santa Ana, San Mamés, San Juan, San Valero o San Julián, las cofradías que aparecen a fines del Quinientos asumen otras más ligadas al espíritu de la Contrarreforma, como sucede con la cofradía de la Sangre de Cristo, Nuestra Señora de la Soledad o el Santo Crucifijo. Partidarias de una mayor austeridad y recogimiento durante las principales festividades del calendario litúrgico, enlazan con el carácter barroco que presidirá las grandes celebraciones religiosas en Daroca durante el siglo XVII. La aprobación de estas nuevas cofradias parece venir más supeditada que las citadas con anterioridad a instancias religiosas y políticas superiores al mero marco ciudadano.

"En lo que han venido a suplicar a la ciudad los confadres de la confradía que se quiere principiar debaxo de inbocación de la Sangre de Cristo, el señor Justicia nombró a Jaime Liñán y a Juan Cerdanya que les respondan, que es: que sin licencia y expreso consentimiento del señor arçobispo y virrey que (espacio en blanco) lo cumnomabere y sin vercarla o provisión de dicho señor arçobispo, que la ciudad no da lugar» ${ }^{15}$.

\subsection{El ciclo festivo pagano. Carnavales y árboles de mayo}

Bastante difuminada en la documentación consultada, muy escasa en detalles, la existencia de fiestas de un carácter más pagano, vinculadas a

14 AMD, Act Mun, 1565, 17 de agosto, 1568, 10 de abril, 1584, 2 de marzo, 16 y 23 de marzo, 1589, 28 de abril, 1591, 16 de abril, 1595, 11 de agosto.

15 Ibidem, 1568, 10 de abril. 
los ciclos de las estaciones, se revela evidente en Daroca. Objeto muy frecuente de atención por parte del Concejo, éste ejercía frente a estas manifestaciones una constante vigilancia con el fin de evitar accidentes, estallidos de violencia o transgresiones de la moral imperante. Caso de resultar estas celebraciones inevitables, el municipio procuraba limitarlas a un período de tiempo concreto, como es el caso del Carnaval.

El Carnaval se adscribe a una serie de fiestas - como la del obispillo o la del abad de los locos - ligadas al invierno, cuya finalidad era siempre la misma: la subversión momentánea del orden establecido que, cimentada sobre antiguos ritos de muerte y renovación, posibilitaba la continuidad de la vida. Esta inversión de valores, tolerada incluso por las autoridades laicas y eclesiásticas, hallará durante la Edad Media y el Renacimiento su mejor cauce de expresión en el Carnaval, festividad en que tendian a desembocar las distintas celebraciones que lo precedían en invierno citadas con anterioridad.

A raíz de los estudios de Bajtín, el Carnaval ${ }^{16}$ ha sido considerado como la expresión más lograda de todo un universo mental de raíz popular caracterizado por la valoración de lo multiforme, material y corporal. Supone, por encima de todo, una exaltación de la risa frente a la seriedad y solemnidad de la cultura oficial, así como una reivindicación del placer frente al rigor transcendente de aquélla. La transgresión de las normas imperantes convertía el tiempo de Carnaval en período muy propicio para la sátira social contra individuos e instituciones, así como para el desarrollo de todo tipo de licencias sexuales y explosiones de violencia.

Si bien es cierto que los primeros testimonios de celebraciones carnavalescas en Daroca se remontan al siglo XVI, parece evidente que éstas contaban con una larga tradición anterior. Las escuetas noticias localizadas aluden al papel regulador del municipio, siempre preocupado por atemperar las desviaciones más graves de la moral imperante. Como expresión de esta actitud, al igual que sucede en otros muchos lugares, el uso de máscaras y disfraces ${ }^{17}$ en Carnaval se intentará prohibir o como

\footnotetext{
${ }_{15}$ Sobre el Carnaval, véase Bajtin, M., La cultura popular en la Edad Media y el Renacimiento. Madrid. Alianza, 1985; CARo BAROJA, J., El carnaval Madrid, Taurus, 1979; HEERS, J., Carnavales y fiestas de locos. Barcelona, Peninsula, 1988, págs. 193-252; MuCHEMBLED, R., Culture populaire et culture des élites dans la France Moderne (xv-xvill siècle). París, Flammarion, 1991, págs. 74-75 y 177-183; BERCE. Y. M., Fête et révolte. Des mentalités populaires du XVI au xvill siècle. Paris, Hachette, 1994, págs. 13-53, y DavIS, N. Z., Sociedad y cultura en la Francia Moderna. Barcelona, Crítica, 1993, págs. 83-112.

La presión contra estas manifestaciones del Carnaval se redoblará durante las últimas dé. cadas del siglo XVI para culminar a fines de siglo con la prohibición de su uso incluso en Carnestolendas. Véase AMD, Act Mun, 1534, 3 de feb, 1550. 31 de enero, 1553, 3 de feb, 1568,
} 
mínimo restringir a los días de Carnestolendas. Con el fin de evitar el estallido de pendencias, el Concejo solía decretar para estas fechas la prohibición de llevar armas de fuego por la ciudad.

«En lo propuesto por el señor Justicia acerca de que no haya máscaras ni echen cohetes por bien de pacificación por que ansí conbiene al servicio de Dios y de su Magestad, todo el Consejo concorde fue de parescer que se veden las máscaras y cohetes. Y se pregone por los lugares públicos y acostumbrados a pena de perder las máscaras y vestidos que llevarán, y presos en la cárcel y castigados a voluntad del consejo y los vestidos sean para el juez que los tomará ${ }^{18}$.

En lo que el señor Justicia ha propuesto lo mucho que se ofende a Dios en los regocijos y fiestas que se suelen hazer el día o dias de Carnestolendas y otras fiestas echando aguas, coetes, vasuras, lodos y otras vellaquerías y desonestidades que enhazer y otras cosas malas y semejantes, y la proybición y veda de las armas y pistoletes y andar de noche en la sen(alada) y otras noches, todo el Consejo lo remite al Concejo para que se haga la ley que bien conviene" 19 .

Tentativa vana. La reiteración de las disposiciones municipales dan buena cuenta de su incumplimiento. Como sucede a nivel general con la cultura popular en Europa durante la centuria ${ }^{20}$, el Carnaval conoce momentos de un auge espectacular en la Daroca del Quinientos. Entre las prácticas carnavalescas condenadas por el Concejo se cuenta el utilizar disfraces y máscaras, disparar cohetes y arrojar agua, lodo y suciedad por calles y casas. Un pregón municipal dictado en febrero de 1568 prohíbe el llevar a cabo danzas de espadas y otros juegos, emplear instrumentos musicales como tambores, flautas, trompetas y cornetas, así como efectuar "otros regocijos deshonestos". La participación de religiosos en las celebraciones carnavalescas se encuentra atestiguada hasta el extremo de cobrar, a veces, carices bastantes violentos: en 1532 un fraile llegará a encabezar una revuelta el día de Carnestolendas.

Vinculada esta vez al ciclo de primavera, se halla documentada también la tradición pagana de plantar un árbol para el mes de mayo con ob-

30 de enero, 1569, 22 de julio, 1576, 8 de febrero de 1577, 1591, 1 de marzo, 1670, 31 de enero, 1677, 29 de enero, 1679, 3 de feb, 1686, 1 de feb, 1690, 1 de feb, 1691, 26 de enero, 25 de feb. 1695, 11 de feb. Sobre la actitud del municipio trente al Carnaval, véase HEERS, J., Carnavales y fiestas de locos. Barcelona, Península, 1988, págs. 208 y 225-252.

18 AMD, Act Mun, 1568, 30 de enero.

Ibidem, 1569, 25 de febrero.

20 Para una caracterización de la cultura popular europea en este período, véase BuRkE, P., La cultura popular en la Europa Moderna. Madrid, Alianza, 1990, págs. 295-315. Para Daroca, véase las dos notas anteriores y AMD, Act Mun, 1532, 23 de feb, 1534, 3 y 15 de feb, 1568, 4 de feb. 
jeto de dar la bienvenida a la primavera y al renacer de la naturaleza que trae consigo. En torno al árbol solían tener lugar bailes y juegos, ocasiones propicias para el desenvolvimiento de una cierta permisividad de carácter sexual muy a tono con la estación. La actitud del Concejo ${ }^{21}$, como ocurría con el Carnaval, se caracteriza por el control y la prohibición - sin mucho afán, bien es verdad- de estas actividades lúdicas. Así, en 1557 el Concejo ordenaba "no poner mayo sin permiso del Justicia». En 1565 y 1568, el municipio disponía de manera taxativa "no hacer ni llevar mayo" bajo severas penas.

\subsection{Corridas de toros, torneos y carreras de caballos}

De una extraordinaria popularidad, la realización de corridas de toros adquirió gran difusión en la ciudad de Daroca ya en la Edad Media ${ }^{22}$. Las Actas municipales del siglo $\mathrm{xV}$ confirman este festejo como práctica habitual. El Concejo darocense encomendaba al arrendador de las carnicerías de la ciudad en el contrato de arriendo el procurar a la ciudad toros bravos o novillos para ser objeto de diversión festiva, consistente en su acoso y enfurecimiento con garrochas hasta su muerte. El municipio habilitaba con cadalsos y barreras el lugar destinado a esta celebración, que tenía ya en el Cuatrocientos su espacio propio: el Campo del Toro, extenso terreno - véase el mapa - situado extramuros de la ciudad, contiguo a la muralla, entre la Puerta Alta y la Torre de los Huevos. Su amplitud lo conformaba como el emplazamiento más apto para "correr los toros" frente a las calles, plazas o ramblas también utilizadas con este fin si las autoridades municipales así lo disponian.

Frente al planteamiento dispuesto en el siglo xv, el Quinientos supone un período de consolidación del espectáculo taurino, de extraordinaria vi-

AMD, Act Mun, 1557, 14 de mayo, 1565, 13 de mayo, 1568, 4 de junio. Sobre el tema, CARo Baroja, J., La estación del amor. Las fiestas populares de mayo a San Juan. Madrid, Taurus, 1979. Las prohibiciones contra la plantación de árboles de mayo por las diversas autoridades en la Francia Moderna son recogidas en MuCHEMbled, R., Culture populaire et culture des élites dans la France moderne (xv-xvil siècle). París. Flammarion, 1991, págs. $184-$ 188

Véase sobre la celebración de los toros en Daroca durante el siglo xv, RodRigo, M. L., "Juegos y festejos en la ciudad bajomedieval. Sobre el correr toros en la Daroca del siglo XV", Aragón en la Edad Media, X-XI (1993), págs. 747-761. Otros testimonios para la ciudad de Zaragoza en FALCON, M. I. Tres efemérides zaragozanas en 1472. Zaragoza, Ayuntamiento, 1976, págs. 18-19, y Sesma, J. A.; San Vicente, A.; Garcia, M. C., y Laliena, C., un año en la historia de Aragón: 1492. Zaragoza, Caja de Ahorros de la Inmaculada, 1992, págs. 450 y 465 470 . 
gencia y popularidad en España durante la Edad Moderna ${ }^{23}$. Éste, favorecido por la buena situación económica, será desarrollado con una mayor asiduidad y se verá sujeto a una mayor reglamentación. Se buscarán nuevos espacios en el ámbito urbano para la lidia y se introducirán innovaciones sustanciales en la misma.

De este modo, si bien se seguirá destinando durante buena parte del Quinientos el Campo de Toro para estas celebraciones, hacia fines de la centuria éstas se irán trasladando hacia otras zonas de la población que cobrarán más amplia difusión en el siglo XVII como escenario de las corridas de toros. Así sucede con la Plaza del Rey o Cristiandad Nueva ${ }^{24}$, donde se correrán toros en 1582 y 1595, o en la Puerta Alta, junto a la ermita de San Marcial, donde tendrán lugar en 1584, 1591 y 1595. Las Puertas Alta y Baja de la ciudad serán los espacios elegidos en principio para el año 1590. Un cierto tono paternalista se desprende de forma bien patente en las disposiciones del Concejo relativas a estas celebraciones:

"Todo el Consejo determinó que se hagan quatro corridas de toros y la primera sea en la Puerta Baja y la segunda en la Puerta Alta. Y las demás vezes, a mayor deliberación. Y remitieron al señor lugarteniente y regidores el hazer las barreras, el tablado para los del Consejo y el enarenar la calle donde se corran. $Y$ que el tablado sea junto a la torre» ${ }^{25}$.

Por norma general, como sucedía ya en el siglo $x v$, los toros se corrian en Daroca para las festividades de San Juan y San Pedro. Con carácter más extraordinario otras celebraciones eran también tenidas en cuenta. Así, en 1532 se celebra una corrida para San Martín, en 1555 para Santa Isabel y para Santiago en 1564. En 1554 se harán barreras para correr toros los dias de San Juan, San Marcial y el Angel Custodio.

Aunque la documentación no ofrece muchos detalles sobre el desarrollo de las corridas de toros, todo parece indicar que la práctica de "garrochar» los toros fue desapareciendo de forma gradual en favor de otras modalida-

\footnotetext{
Véase, en general, Defourneaux. M. La vida cotidiana en la España del Siglo de Oro. Madrid, Argos Vergara, 1983, págs. 130-132. A nivel particular, BENNASSAR, B., Valladolid en el siglo de Oro. Una ciudad de Castilla y su entorno agrario en el siglo xvi. Valladolid. Ayuntamiento, 1989, págs. 442-445; ChACón, F., Murcia en la centuria del Quinientos. Murcia, UniversidadAcademia Alfonso X el Sabio, 1979, págs. 434-436, LOPE TOLEDO, J. M., "Logroño en el siglo XVI: toros y cañas", Berceo, 68 (1963), págs. 257-277. Para Daroca, Martinez, F. J., "Aspectos taurinos en la Historia de Daroca". Daroca, Programa de las Fiestas del Corpus, 1993.

24 AMD, Act Mun, 1582, 13 de julio, 1584, 28 de junio, 1595, 9 y 23 de junio y APND, 1590. Asensio Martinez (796), 10 de julio.

z5 APND, 1590, Asensio Martínez (796), 10 de julio.
} 
des taurinas ${ }^{26}$. En 1563 con motivo de la llegada de Felipe II a la ciudad se correrá un toro con jubillos, es decir, con un armazón de madera sobre la cabeza en cuyos extremos ardían sendas bolas de pez. Para la ocasión se trajeron también "ahochadores" de Villafeliche. Esta variante, consistente en sujetar al toro con una gruesa maroma, se volverá a repetir a fines de siglo en años como 1591 ó 1596. Ambas modalidades, los toros "enxubilladoS" o ensogados adquirirán amplia difusión en Daroca durante el siglo XVII.

Como también sucedía en la época medieval, en Daroca tenían lugar durante el Quinientos varias carreras de caballos a lo largo del año. Éstas se solían desarrollar en la rambla o carrera de los caballos, vecina al Campo del Toro, con ocasión de las tres ferias existentes en la ciudad: el Corpus, San Mateo y San Andrés. Pese a no conservarse descripciones del festejo, parece que se trataría de un juego de habilidad: de escaramuzas o de cañas. La vigencia en el siglo XVI de las disposiciones medievales que obligaban a los ciudadanos a presentar caballo y armas el día de San Martín como condición necesaria para acceder a los principales oficios de la ciudad, configuraría a estos "mostrantes» como los protagonistas de la exhibición hípica.

Vinculadas a estos festejos deportivos, pero con carácter más ocasional, se aprecia para la segunda mitad del Quinientos la celebración de torneos en la ciudad ${ }^{27}$ en fechas que suelen coincidir con el ambiente festivo del Carnaval. En febrero de 1555 el Concejo ordena construir un palenque "para un torneo de Carnestolendas", de posible carácter burlesco. El nacimiento de un nuevo infante de la Casa de Austria, el príncipe Felipe, es saludado en febrero de 1572 por el Consistorio con la organización de un torneo y otras celebraciones. A fines de enero de 1577 el municipio provee los costes de cubrir con arena el espacio donde se habia desarrollado un torneo consistente en alancear a caballo el escudo de un muñeco giratorio -estafermo- provisto en su otra extremidad de bolas sujetas con correas, práctica también documentada para las primeras décadas del siglo XVII.

\subsection{Representaciones teatrales}

Herencia de los entremeses desarrollados en la ciudad en el siglo xv para el Corpus Christi, el amplio registro de manifestaciones teatra-

26 AMD, Act Mun, 1563, 10 y 29 de oct 1565, 18 de febrero, 1591, 19 de julio, 6 de sept, 1596. fol. 103v. Sobre los diversos juegos y de corridas de toros, véase Caro Baroja, J.. El estio festivo. Fiestas populares de verano. Madrid, Taurus, 1984, págs. 291-311.

AMD, Act Mun,1555, 22 de feb,1572, 20 de feb y 1576, 25 de enero de 1577. 
les ${ }^{28}$ constatadas en Daroca supone una de las manifestaciones culturales más interesantes de la ciudad durante el Quinientos. Su difusión tan notoria se constituye en testimonio evidente del importante papel desempeñado por las pequeñas poblaciones, más ligadas al mundo rural, como sustento del teatro en la España del Siglo de Oro.

Un primer campo de desarrollo de la actividad teatral en la ciudad viene dado por la representación de dramas litúrgicos en el interior de iglesias y conventos, característica propia del teatro castellano del siglo XVI con respecto al resto de Europa occidental, donde esta costumbre había ya desaparecido ${ }^{29}$. Así, ya en enero de 1529 el municipio darocense nombra una comisión para hablar con los canónigos de Santa María para "que se faga la pasión de San Blas", muestra indudable del arraigo de la veneración por el santo en la localidad. Esta manifestación parece enlazar con el teatro religioso del Quinientos estudiado por Wardropper y Flecniakoska ${ }^{30}$, cuya temática se halla asociada a episodios de la vida de Jesucristo y de los santos, así como al culto de la Virgen María y del Santo Sacramento. Todavía en enero de 1588 el municipio proveerá de tambores y trompetas a los canónigos de Santa María para que puedan realizar una representación o "lstoria" del Santísimo Misterio, espectáculo quizás propiciado por la necesidad de allegar limosnas destinadas a sufragar las importantes obras de ampliación de la iglesia Colegial efectuadas en aquel momento.

La segunda vía de expansión viene de la mano del mundo de la enseñanza ${ }^{31}$. Daroca disponía desde la Baja Edad Media de un estudio de Artes, al que acudían a formarse decenas de jóvenes, procedentes tanto de la comarca circundante como de la misma ciudad. Algunos de estos estu-

28 Sobre el origen medieval del teatro y su evolución en España durante los siglos XVI y XVII, véase Shengol.o, N. D., A History of the Spanish Stage. From Medieval Times until the End of the Seventeenth Century. Londres, Claredon y Oxford University Press, 1987. Para Aragón, EGido, A., Bosquejo para una historia del teatro en Aragón hasta finales del siglo xvIti. Zaragoza, Institución Fernando el Católico, 1987. Sobre Daroca, MATEOS, J. A., "Municipio y teatro en Daroca (siglos XVXvil): de los entremeses del Corpus a la Casa de Comedias", Criticón. 68, (1996), págs. 7-30 y "Teatro y sociedad en la Daroca del Cuatrocientos: la Istoria de los Sanctos Corporales" Edad de Oro, XVI (1997), págs. 221-234

AMD, Act Mun, 1529, 29 de enero y APND, 1587, Tomás Zorrilla (1479), 15 de enero de 1588 y 1587 , Miguel Domingo de Latorre (751 bis), 20 de enero.

30 WARDROPPER, B. W. Introducción al teatro religioso del Siglo de Oro. La evolución del auto sacramental (1500-1648). Salamanca. Anaya, 1967 y FLECNIAKOSKA, J. L., La formation de lauto religieux en Espagne avant Calderon (1550-1635). Montpellier, Imp. Paul Dehon, 1961.

AMD, Act Mun, 1569, 20 de mayo, 1596, 26 de mayo. Sobre el tema, entre otros, Garcia SoRIANO, J., El teatro universitario y humanístico en España. Toledo, Talleres tipográficos de Don Rafael Gómez Menor, 1945 y Hermenegildoo, A., La tragedia en el Renacimiento español. Barcelona, Planeta, 1973. 
diantes representarán para el Corpus de 1569 "por mandado de la ciudad" una comedia en latín. La educación elemental, potenciada de forma creciente por el Concejo a lo largo del XVl, también participará en el teatro. De nuevo para el Corpus, los niños de la escuela, adoctrinados por el maestro encargado de enseñarles a leer y escribir, realizarán una representación en 1596.

Otro grupo social bien configurado que motivó la intervención del Concejo respecto a sus representaciones teatrales fueron los moriscos ${ }^{32}$. Entre las medidas dictadas con motivo de la conversión forzosa de los mudéjares en febrero de 1526 se incluye: "Si alguna farsa se hará que no les comprenda, con voluntad del Justicia”. Esta disposición municipal suponía el control sobre las representaciones en lengua aljamiada con el doble motivo de restringir estas manifestaciones culturales y de evitar que fuesen utilizadas por los moriscos para transmitir noticias del Norte de Africa que pudiesen fomentar una rebelión. Por esta última razón ordenará el Concejo en mayo de 1587 "que una representación que los nuevos convertidos quieren hacer, que no la hagan".

Junto a estas representaciones ligadas a las habitantes de la ciudad, el Concejo empezará a conformar a partir de mediados de siglo, en sintonía con el proceso vivido en el resto de la Península y en otros países de Europa, diversas iniciativas ligadas a representaciones por parte de actores itinerantes laicos. La primera constatación data de 1550 al costear el municipio los gastos de construir un teatro para representar la Asunción el día de Nuestra Señora de Agosto, así como al sufragar en octubre la escenificación de una farsa ${ }^{33}$. La iniciativa se verá refrendada en la década de los sesenta al propiciar el Concejo en diversas ocasiones el desarrollo de escenificaciones - 1564, 1569-, tanto por forasteros como por habitantes de Daroca. Se hace evidente a todas luces el interés del municipio por encauzar estas representaciones vinculadas a la gestación de la comedia en España para someterlas a unas pautas de control y a un cierto calendario.

Un buen ejemplo de esta influencia es la práctica, por parte de las compañias teatrales, de realizar una primera representación -la muestrade la obra que se pensaba escenificar en la localidad ante los miembros

37. AMD. Act Mun, 1526, 25 de feb y APND, 1587. Tomás Zorrilla (1479), 8 de mayo. Véase sobre el tema, YNDURAIN, F., Los moriscos y el teatro en Aragón. Auto de la destrucción de Troya y Comedia pastoril de Torcato. Zaragoza, Institución Fernando el Católico, 1986.

33 AMD. Act Mun, 1550, 17 de agosto, 10 de oct, 1564, 18 de oct, 1569, 16 de abril, 20 de mayo. 
del Concejo en las "Casas de la ciudad " o Consistorio ${ }^{34}$, sito frente a la iglesia de Santa María — véase el mapa adjunto-. La actuación permitía al municipio no sólo tener un conocimiento previo de la obra antes de conceder la licencia necesaria para su representación, sino también determinar la tasa que podían percibir los comediantes de cada persona por contemplar la obra. Este comportamiento, en completo acuerdo con el intervencionismo municipal más marcado característico de las pequeñas poblaciones, parece afirmarse en fechas bastante tempranas. Como acredita el texto anexo, fechado en 1569, su grado de influencia podía incluir el fijar el número de representaciones.

«En lo que el señor Justicia ha propuesto acerca del darle licencia a unos estrangeros para hazer una comedia y recitarla, todo el Consejo concorde son de parecer que se de licencia para que se haga y remiten al señor Justicia la tasa que han de llevar a los que la quisieren ver y el tiempo que ha de exercitarse en Daroca» ${ }^{35}$.

Un segundo punto de interés es la voluntad, por parte del Concejo, de asegurar que la ciudad va a contar con la escenificación de comedias en unas fechas determinadas, entre las que destacan la del patrón de la ciudad, Santo Tomás de Aquino, el Corpus y Nuestra Señora de Agosto ${ }^{36}$. Coincide en resumen con la importancia otorgada por Nöel Salomon y otros autores ${ }^{37}$ a las festividades que se desarrollan en los pueblos y pequeñas ciudades entre mayo y septiembre para la celebración en estos centros rurales de representaciones teatrales. Respecto a los temas desarrollados por éstas, la información es escasa; pero parece plausible pensar que, junto a la escenificación de comedias de carácter profano, la ocasión propiciaba el tema religioso cuando no el auto sacramental. Así, en 1550 , con motivo de la fiesta de Nuestra Señora de Agosto, se represen-

34 AMD, Act Mun, 1564, 18 de oct, 1589, 31 de agosto, 1591, 23 de feb, 1593, 6 de agosto, 1595, 24 de nov, 1605, 2 de dic, 1608, 8 de agosto, 1613, 8 de abril, 1617, 10 de enero, 11 de abril, 1618,12 de oct.

Ibidem, 1569, 16 de abril.

Ibidem, 1550, 17 de agosto, 1569, 20 de mayo, 1589, 31 de agosto, 1591, 1 y 8 de marzo. 1595,3 y 10 de marzo, 1596, 26 de mayo, 1600, 12 de mayo, 1608, 8 de agosto, 1616, 9 de agosto y APND, 1587, Tomás Zorrilla (1479), 10 de marzo.

Véase SALOMON, N, "Sur les representations théatrales dans les pueblos des provinces de Madrid et Tolede (1589-1640)", Bulletin Hispanique, LXII (1960), págs. 398-427; PASCUAL. M. T., Teatros y vida teatral en Tudela, 1563-1750. Estudio y documentos. Londres, Támesis, 1990 , págs. 43-44; SANCHEZ Romeralo, J., “El teatro en un pueblo de Castilla en los siglos XVI y XVII: Esquivias, 1588-1638", en Diálogos Hispánicos de Amsterdam, 2 (1981), págs. 39-63, y HiGES, V., "El patio de comedias de Soria y sus representaciones en el siglo XVII", Celtiberia, XVI, 32 (1966), págs. 239-250. 


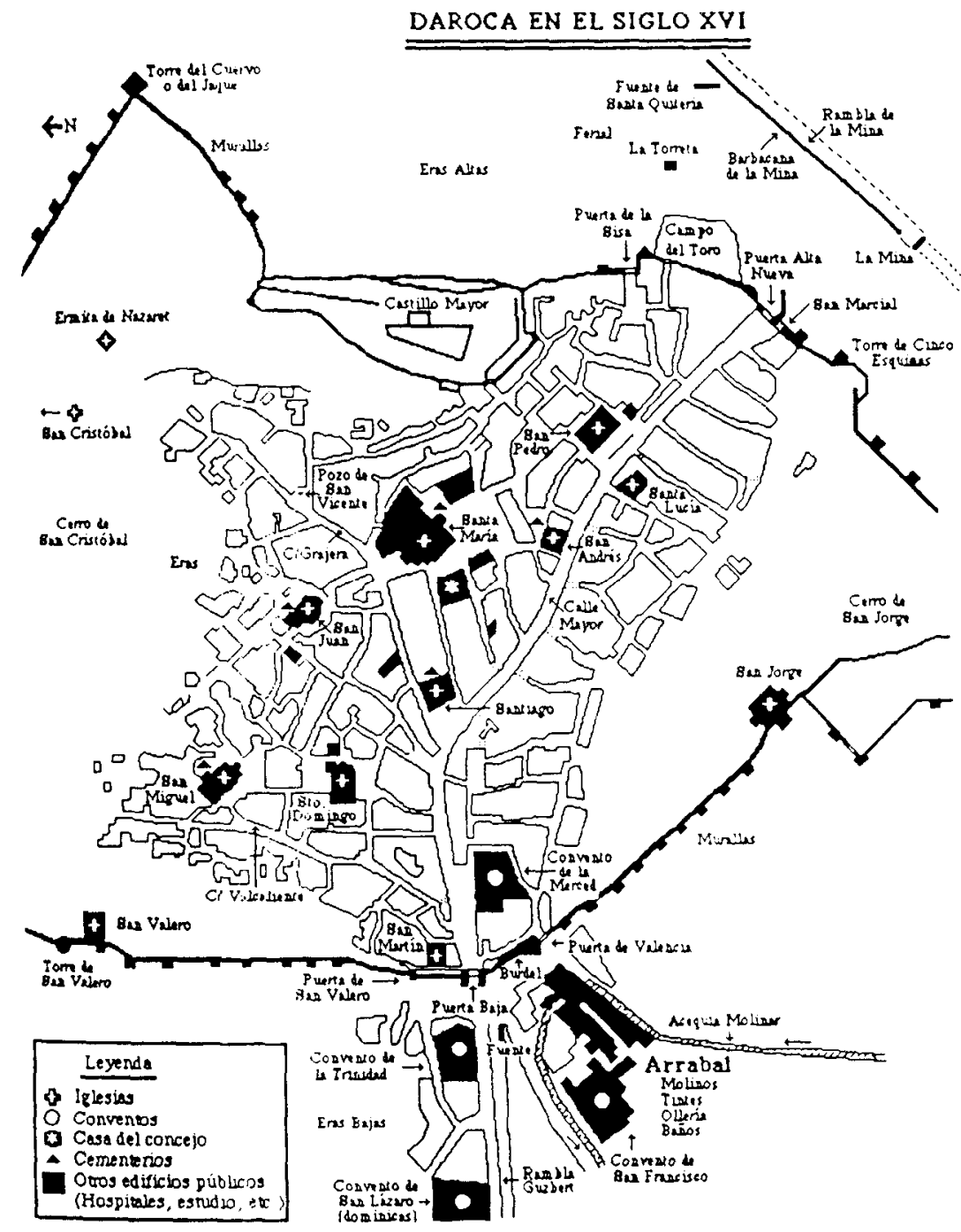

Según CoRral, J.L., "Catástrofes naturales y transformaciones urbanas en la ciudad de Daroca en los siglos XV y XVI», Aragón en la Edad Media, Zaragoza, X-XI (1993), pág. 195. 
tará el muy apropiado tema de la Asunción de la Virgen. En marzo de 1587, para Santo Tomás de Aquino, una comedia a lo divino. En mayo de 1600 , la ciudad gratificará a Basilio Sánchez por la construcción de un tablado "para la comedia de(l) señor San Jorge".

El interés del municipio, expresión segura del arraigo de un cierto gusto popular por estas actuaciones, se verá favorecido desde fines del XVI por la consolidación definitiva de la Casa de Comedias de Zaragoza ${ }^{38}$, fijada en 1589. Su presencia garantiza la continuidad de una demanda estable de representaciones por el público zaragozano que favorece el surgimiento de compañias teatrales. Estas tendrán en cuenta con rapidez la demanda rural, atendida durante los desplazamientos de ciudad en ciudad o durante el verano, con motivo del gran número de fiestas celebradas para estas fechas en el campo. Resultado final de esta dinámica, el municipio establecerá en 1616 con Luis de Masarte un acuerdo para que estableciese una Casa de Comedias en la ciudad ${ }^{39}$, donde actuarán a lo largo del Seiscientos compañías de paso.

\section{LOS FESTEJOS EXTRAORDINARIOS. LA VINCULACIÓN CON LA MONARQUIÁA}

Al margen de las principales fiestas asociadas a la ciudad, otros acontecimientos de carácter más externo motivaban manifestaciones de júbilo por parte de la ciudad. Vienen determinados al pretender el Concejo expresar por medio del espectáculo el sentimiento de la ciudad frente a ciertos acontecimientos, por lo general relacionados con la institución monárquica. El municipio manifestaba así sus vínculos con el rey o el reino a través de pautas ceremoniales ya establecidas, tanto en Aragón como en Castilla, durante la Baja Edad Media ${ }^{40}$. La verdadera novedad es la mag-

38 Sobre la Casa de Comedias de Zaragoza, véase SAN VICENTE, A., "El teatro en Zaragoza en tiempos de Lope de Vega", en Homenaje a Francisco Yndurain. Zaragoza, Universidad, 1972, págs, 267-361, y GONZALLZ HERNANDEZ, V., Zaragoza en la vida teatral hispana del siglo xvil. Zaragoza, Institución Fernando el Católico, 1983. Véase también GIMÉNEZ SOLER, A., "El teatro en Zaragoza antes del siglo XIX», Universidad, IX (1927), págs. 243-396 y 571-648.

39 AMD, Act Mun, 1616, 25 de sept y 20 de nov.

40 Véase en general sobre España Rucouol, A. ed., Realidad e imágenes del poder. España a fines de la Edad Media. Valladolid, Ámbito, 1988. Para Castilla, NIETO, J.M., "Apología y propaganda de la realeza en los cancioneros castellanos del siglo Xv". En la España medieval, 2 (1988), págs. 185-221; MACKAY, A., "Ritual and propaganda in fifteenth century Castile», Past and Present, 107 (1985), págs. 3-43, y ANDRÉs DIAZ, R., "Las entradas reales castellanas según las crónicas de la época", En la España medieval, IV (1984), págs. 47-62. Sobre Valencia, NArBona, R., "Las fiestas reales en Valencia entre la Edad Media y la Moderna (siglos XIV-XVII)", Pedralbes, 
nificencia y suntuosidad de la que se dota a estos ceremoniales a lo largo de los siglos del Renacimiento y del Barroco.

De hecho, como característica general a lo largo del Quinientos, se percibe la adopción de un distinto planteamiento por el Concejo cara al fenómeno festivo. En el Cuatrocientos, el municipio dirige su mayor atención - y sus principales gastos - a fiestas ligadas a la ciudad como la Rolda de Septiembre y el Corpus. La supresión en 1484 de la "Istoria de los Sanctos Corporales» celebrada para el Corpus y la de las «alegrias de la Rolda" ${ }^{41}$ al año siguiente suponen un evidente retroceso en la contribución municipal a las principales fiestas locales, centrada durante los siglos XV1 y XVII en la conmemoración de Nuestra Señora de Agosto. Como se convierte en norma general en las ciudades españolas durante el Antiguo Régimen ${ }^{42}$, serán las fiestas de exaltación de la monarquía las que retengan en mayor medida la atención del Concejo darocense.

La misma monarquía, por mediación de virreyes y gobernadores, mantenía vivos estos vínculos con las ciudades de sus diversos reinos mediante la remisión de misivas. El anuncio de felices nuevas se veía acompañado de la solicitud de conmemorar con grandes manifestaciones de júbilo victorias militares o acontecimientos familiares vinculados a la Casa de Austria, como el alumbramiento de infantes o los esponsales de reyes o príncipes. El Concejo se convertía así, por medio de las diversas celebraciones públicas, en cauce transmisor de la buena salud y alegría de la monarquia, que debia ser compartida por sus súbditos, de igual modo que

13 (1993), tomo II, págs. 463-480. Para el reino aragonés, LALIENA, C. y IRANZO, T., “Las exequias de Alfonso $V$ en las ciudades aragonesas. Ideología real y rituales públicos", Aragón en la Edad Media, IX (1991), págs. 55-75. Sobre Daroca, Garcia MarCo, L. F., y Garcia Marco, F. J., "El impacto de la muerte del príncipe Juan en Daroca (1497-1498): Poesía elegiaca y ritual urbano", Aragón en la Edad Media, X-XI (1993), págs. 307-337 y RoDRIGO, M. L., “El poder real y los ri. tuales públicos de exaltación de la monarquía en una ciudad aragonesa: Daroca (1449-1525)", en Actas del XV Congreso sobre Historia de la Corona de Aragón, tomo 1, vol. 3. Zaragoza, Diputación General de Aragón, 1996, págs. 461-478.

${ }^{41}$ Véase sobre estas celebraciones, Rodrigo, M. L., Poder y vida cotidiana en una ciudad bajomedieval: Daroca, 1400-1526 (tesis doctoral inédita).

4? Bennassar, B., Valladolid en el siglo de Oro. Una ciudad de Castilla y su entorno agrario en el siglo XVI. Valladolid, Ayuntamiento, 1989, págs. 435-452; Chacon, F., Murcia en la centuria del Quinientos. Murcia, Universidad y Academia Alfonso $X$ el Sabio, 1979, págs. 425-439, y en general PedRazA, P., Barroco efímero en Valencia. Valencia, Ayuntamiento, 1982. Como consecuencia, los gastos en fiestas tenían una importante repercusión sobre las haciendas de los municipios. Véase BENNASSAR, B., Valladolid en el siglo de Oro. Una ciudad de Castilla y su entorno agrario en el siglo xvi. Valladolid, Ayuntamiento, 1989, págs. 451-452; Gutiérrez Alonso, A., Estudio sobre la decadencia de Castilla. La ciudad de Valladolid en el siglo xvil. Valladolid. Ayuntamiento, 1989, págs. 378-379, y Bustos, M., "La hacienda municipal gaditana en el reinado de Carlos IIl", Gades, 9 (1982), págs. $43-44$ 
acontecimientos luctuosos daban lugar a manifestaciones de duelo y a la prohibición de todo festejo.

De este modo ${ }^{43}$, Daroca conmemora el año 1525 el apresamiento del rey Francisco I en la batalla de Pavía, así como el enlace de Carlos $V$ con Isabel de Portugal mediante músicas, procesiones y fuegos artificiales. En octubre de 1554 el municipio ordena una procesión para celebrar las nuevas de la feliz llegada a Inglaterra del principe Felipe con objeto de contraer nupcias con María Tudor. En 1572 el nacimiento del infante Felipe, heredero del trono, desata importantes festejos en la ciudad. En 1545, la muerte de la princesa Maria de Portugal, esposa del futuro Felipe II, como consecuencia de un parto troca en luto las iniciales disposiciones festivas desencadenadas por el alumbramiento.

Ahora bien, será con motivo de las entradas reales en Daroca cuando mejor se perciba la progresiva evolución del municipio hacia un ceremonial más suntuoso y recargado ${ }^{44}$. De este modo, las entradas en la ciudad del emperador Carlos I en 1522 o de la emperatriz Isabel en 1534 no motivaron al Concejo, de acuerdo con la tradición medieval, costes de relieve. De forma bien distinta ocurrirá con las diversas visitas - 1563, 1578, 1585realizadas por Felipe II a Daroca, que introducen una concepción del espectáculo festivo mucho menos austera, más rica, variada y acorde con la bonanza de los tiempos.

Así, la entrada de la reina Isabel de Portugal en Daroca en 1534 enlaza de forma perfecta con anteriores celebraciones descritas para la Daroca del Cuatrocientos. Las calles eran limpiadas y dispuestos tapices y colgaduras en las fachadas por donde debía transcurrir el cortejo real. Escoltada por nuncios y maceros, la soberana entra bajo palio. Signo visible de soberania, dado que su uso quedaba restringido al rey y su esposa ${ }^{45}$, el palio definía el orden de la procesión y desataba en torno al mismo las habituales disputas por cuestiones de preeminencia.

“Propuso el señor Justicia havía necessidat prover en la entrada de la Emperatriz Nuestra Señora qué orden se devia tener por quando entró en febrero.

42. AMD, Act Mun, 1525, 17 de marzo, 28 de nov, 1545, 24 de julio, 21 de agosto, 1572, 20 de

44 Ibidem, 1522, 1 de agosto, 1534, 8,11, 14 y 17 de enero, 1563, 13 y 28 de agosto, 10 y 29 de oct, 1565, 18 de febrero, 1578, 21 de mayo, 6 de junio, 11 de agosto, 30 de noviembre, 1584 , 18 de nov, 28 de dic.

${ }_{45}$ Véase AndRES Diaz, R., "Las entradas reales castellanas según las crónicas de la época", En la España medieval, IV (1984), pág. 54, y SESMA, J. A., "Una reina de Aragón en Castilla: el recibimiento castellano a Germana de Foix en 1507 según un testigo aragonés". Anuario de Estudios Medievales, 19 (1989), pág. 687. 
Calatayud hovo differencia entre el governador y el Justicia, qual de ellos entraría a la mano derecha, que el Consejo viessen la forma que se devía tener. Fueron de parecer se diputen personas para ordenar lo que se devia hazer. Y el Justicia diputó a Sthevan Lop, Joan Romeo y Luis de la Abadía para que ordenen lo que cumple a la honra de la ciudat" ${ }^{46}$.

Ya en la segunda mitad de la centuria, al conocerse la llegada de Felipe II, el Concejo ordenaba reparar los caminos y decorarlos con enramadas, y enviaba una delegación para acompañar al rey y su séquito, al cual dotaba de vituallas. Tras la entrada del monarca en la ciudad, bajo palio y saludada con salvas, se desarrollaban en su interior diversos actos en su honor, como bailes o corridas de toros. En 1563, por ejemplo, se efectúa ante el rey una danza de arquillos, así como diversos bailes en las calles de Grajera y Valcaliente, ante la iglesia de San Pedro y en la Cristiandad Nueva. Como muestra de hospitalidad, el Concejo entregaba presentes a la familia real y costeaba su alojamiento. La culminación de estas fiestas se alcanza a fines de siglo en años como 1578, cuando Daroca decide imitar el ejemplo de las mayores ciudades del reino como Zaragoza ${ }^{47}$. La Corporación y "los criados de la ciudad»-músicos, nuncios, maceros-, según deseo del rey, recibirán vestiduras nuevas y libreas a cuenta del municipio para festejar el hecho. Un arco triunfal se erigirá para recibir al monarca.

"Todo el Concejo fue de parecer que en la entrada y recibo de su Magestad, del rey Nuestro Señor, se haga todo el regocijo posible haziendo enramadas por el camino por donde tiene de entrar. $Y$ hazer danças y baylas y otras inventiones. $Y$ en las torres tener tiros y escopetas, y tirar con ellas al tiempo que su Magestad entre" ${ }^{48}$.

Todo el Concejo concorde fue de parecer se haga un arco y desde la puente del río Mayor hasta la ciudad se planten fazedas y enramadas hechando por el suelo, y otras yerbas frescas" ${ }^{49}$.

En evidente contraste con el siglo XVII, cuando nobles familiares de la Casa de Austria y personajes de relieve dentro del reino aragonés son objeto de halago continuo por el Concejo darocense como expresión de su

AMD, Act Mun, 1534, 11 de enero.

Véase en general sobre el tema, Serrano, E.. "Fiestas y Ceremonias en la Edad Moderna: Fuentes y Documentos para su estudio", en Actas de las VIII Jornadas de Metodologia de la investigación científica en fuentes aragonesas. Zaragoza. Universidad, 1993, págs. 72-157. Compárese con las entradas reales descritas en MARSDEN, C.A., "Entrées et fêtes espagnoles au xv siècle", en Jaconot, J. ed., Les fêtes de la Renaissance, vol. II, Paris, CNRS, 1960, págs. 389-411.

AMD. Act Mun, 1563, 28 de agosto.

Ibidem. 1578, 21 de mayo. 
mayor dependencia política ${ }^{50}$, en el Quinientos la figura del monarca es la única que desata manifestaciones de homenaje y aparato. Sólo de manera excepcional, la llegada de algunos arzobispos a la ciudad provoca celebraciones más modestas, que incluyen manifestaciones festivas más vinculadas a lo cotidiano, como es la participación de cofradias. Su presencia, más señalada a fines de siglo, parece abrir cauce a la decisiva participación de la Iglesia en los ritos de exaltación de la Casa de Austria que tendrán lugar en la Daroca del siglo XVII.

\section{CONCLUSIONES}

A lo largo del presente estudio se ha asistido a la exposición de las principales manifestaciones festivas de la ciudad de Daroca durante el siglo xvI. En su mayoría, manifiestan la indiscutible plenitud de la cultura popular vivida en Europa a lo largo de esta centuria. La importancia de las manifestaciones religiosas no esconde la presencia de indudables prácticas ligadas al ciclo festivo pagano, que de manera literal se desbordan en la Daroca del Quinientos. Corridas de toros y carreras de caballos compiten en popularidad con el gusto por el teatro. Las representaciones teatrales, en concreto, muestran una diversidad tal en el seno de la ciudad que indican la conveniencia de incrementar los estudios sobre estas pequeñas poblaciones, mas ligadas al mundo rural, como cauce de desarrollo del teatro en la España del Siglo de Oro.

Junto a las celebraciones populares, se percibe el progresivo despliegue de las conmemoraciones vinculadas a la Casa de Austria. Favorecidas por el auge económico general de la centuria y el recurso al endeudamiento por el Concejo, éstas se tornan cada vez más esplendidas a partir de mediados de siglo. Las entradas reales, en especial, son proyectadas con mayor cuidado hasta llegar a adoptarse en ocasiones motivos de clara influencia italiana, como el arco triunfal, muy al uso en las grandes ciudades españolas y europeas de la época. Al margen de sus manifestaciones más aparatosas, estas celebraciones no dejan de integrar aspectos de la cultura popular dentro del tono general festivo que preside el siglo XVI.

En definitiva, las denominadas cultura popular y oficial muestran una situación de plena convivencia en Daroca durante el Quinientos. Sin em-

56. Matros, J. A., "Política municipal y ceremoniales públicos: la exaltación de la monarquía en la Daroca de los Austrias (siglos xvi-xvII)", Jeronimo Zurita, 72, (1996), págs. 131-152 
bargo, la progresiva irrupción de la Contrarreforma en las últimas décadas de la centuria irá absorbiendo las diversas manifestaciones populares para imponer un tono religioso más marcado y depurar los matices paganos. La apelación al sentimiento trágico del Barroco y el pleno sometimiento del municipio a los objetivos de la monarquía acrecentarán ya en el Seiscientos el sentido político-religioso de las celebraciones públicas, así como el predominio de las exequias fúnebres por la Casa de Austria sobre las conmemoraciones festivas. Hacia fines del siglo XVII, sometida en mayor medida a los cauces de las celebraciones oficiales, la cultura popular, pese a mantenerse, habrá perdido el vigor característico de la centuria del Quinientos.

\section{APÉNDICE DOCUMENTAL}

Documento 1. Archivo Municipal de Daroca. Actas Mun, 1569, 4 de febrero. Bando dictado por el Concejo darocense contra ciertas prácticas de Carnaval.

Eodem die, Miguel de Viota, nuncio, hizo relación que por mandato de Consejo havia pregonado el presente cartel escrito de mano del señor Justicia sub tali sig (signo de cruz) no por los lugares públicos y acostumbrados de dicha ciudad mediante las trompetas. $Y$ fueron testigos Miguel Texedor y Juan Soriano, lo qual havía hecho el primero de febrero deste presente año. Et el qual cartel es del tenor siguiente:

Oyd, que os hacen saber de parte y por mandamiento del señor Justicia, Juez, jurados, officiales y Consejo de la presente ciudad de Daroca a todos los vezinos y havitadores della que, atendido los grandes daños, inconbenientes, muertes de personas, incendios de cassas y grandes enojos y escándalos que se siguen y pueden seguirse en gran deservicio de Dios Nuestro Señor y de la Majestad real del Rey Nuestro Señor en consentirse hagan máscaras y disfraces, y echar cohetes y hazerse danças d'espadas y otros juegos y disfraces con atambores, flautas y otros instrumentos de trompeta, corneta y otros regocijos desonestos. Por tanto, se intima con público pregón que ninguno sea osado de hechar cohetes dentro de la presente ciudad ni en sus arrabales ni a la redonda de los monasterios, a pena de ser llevados a la cárcel y estar apresionados en ella tanto tiempo quanto al Consejo parescerá y de sesenta sueldos para el oficial que lo executará

Item ansimesmo se manda y veda que ninguna persona sea osado de hazerse máscaras en la ciudad ni en los lugares susodichos a pena de 
perder la máscara y sus ropas y adreços que sobre sí llevare, los quales sean del oficial real que los prendiere y los llevare a la cárcel, donde hayan de estar presos hasta que el Consejo de la dicha ciudad les mande castigar como desobedientes a los mandamientos de su Magestad y de los oficiales reales.

Documento 2. Recibimiento del rey Felipe II. Archivo Municipal de Daroca, Act Mun, 1578, 6 de junio.

En lo que el señor Justicia ha propuesto acerca la venida de sus Magestades ay necesidat de reparar los caminos, todo el Consejo concorde fue de parecer se nombren personas para adobar y reparar los caminos. Y assí el señor Justicia, de voluntad del Consejo, nombró para dicho efecto a Antón Porter y Bartholomé de Viota probeyendo el gasto mandando al procurador pague aquél conforme a la deliberación del Concejo.

En lo que el señor Justicia ha propuesto acerca de la necesidad que se ofreçe de que las personas que han de llebar el palio y palafreneros y el señor Justicia bayan con ábito decente y qual conviene a tal efecto y al servicio de su Magestad y authoridad de la ciudad, satishaziendo, cumpliendo y obedeciendo a las cartas de su Magestad y el señor virey, y de lo que a boca ha dicho y encargado el señor vicecanciller al señor Justicia y oficiales del govierno y consejo de dicha ciudad.

Todo el Consejo concorde fue de pareçer se cumpla la voluntad de su Magestad. $Y$ para dicho efecto se nombren personas iuxta el poder por el Concejo dado. Y assí el señor Justicia, de voluntad de dicho Consejo, nombró para dicho efecto a los señores Joan Baptista de Bello, Sebastián Franco, Domingo Durango, Martín de Arándiga mayor, a los quales concorde 0 a la mayor parte dellos, con intervención del dicho señor Justicia, el dicho Consejo les dió todo poder cumplido como el Concejo lo tiene para gastar lo que bien convenga y visto les fuere convenir para el servicio de sus Magestades y authoridad y honra de la dicha ciudad, probeyendo el gasto necesario que se ofreçiere aora por entonces para lo sobredicho, mandando al procurador de la ciudad pague aquél conforme a la deliberación del Concejo, quales juraron. (...)

Todo el Consejo concorde fue de parecer se haga un arco. $Y$ desde la puente del río mayor hasta la ciudad se planten fazedas y enramadas hechando por el suelo, y otras yerbas frescas. $Y$ para el dicho efecto, el dicho señor Justicia nombró, de voluntad del Consejo iuxta el poder del Concejo. Para lo del arco triunfal nombró el dicho señor Justicia a los señores Anthonio de Orera, Sebastián Franco, Joan de Alberuela y 
Bartholomé de Viota, a todos o a la mayor parte dellos para lo sobredicho, y reparar las casas en la calle que conviniere, derribar casas peligrosas. Y para enramadas y caminos nombró el dicho señor Justiçia a los señores Antón Ported y Domingo de Heredia mayor, dándole poder cumplido. Y probeyeron el gasto mandando al procurador general pague aquél iuxta el poder del Consejo y Concejo. 